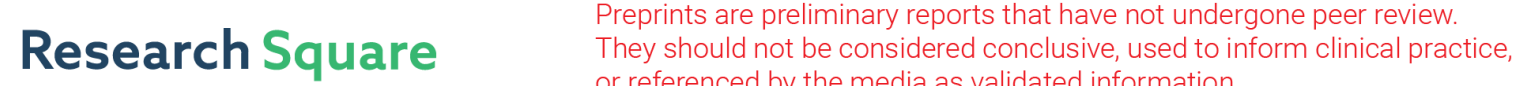 or referenced by the media as validated information. \\ The Effect of Health System Responsiveness on Health Outcome: Evidence from Spain
}

Solomon Kibret Abreha ( $\sim$ abegenik.09@gmail.com )

Research article

Keywords: Health system responsiveness, Self-assessed health, Reporting heterogeneity, anchoring vignettes, Spanish Healthcare Barometer

Posted Date: January 13th, 2020

DOI: https://doi.org/10.21203/rs.2.20759/v1

License: (c) (1) This work is licensed under a Creative Commons Attribution 4.0 International License. Read Full License 


\title{
The Effect of Health System Responsiveness on Health \\ Outcome: Evidence from Spain
}

\author{
Solomon Kibret Abreha ${ }^{1}$
}

${ }^{1}$ Department of Economics, University of Insubria, Varese, Italy

Corresponding author

Solomon Kibret Abreha,

Phone: +393498527595

e-mail: abegenik.09@gmail.com 


\section{Abstract}

Background: For the last two decades, the health system responsiveness has gained attention in the health policy area. However, little is known about its effect within the healthcare system on health outcome. This study aims to investigate the influence of health system responsiveness on self-assessed health. Particularly it examines if self-assessed health is affected by satisfaction with communication, dignity and waiting time.

Methods: The study used data from the Spanish Health Care Barometer Survey (SHBS) between 2011 and 2013. The Ordered Probit and the Hierarchical Ordered Probit (HOPIT) model was used to model anchoring vignettes and to control the problem of reporting heterogeneity arises from self-reported health.

Results: The result suggests a strong positive association between reporting very good self-assessed health and most of the domains of health system responsiveness. Specifically, after adjusting for reporting heterogeneity, satisfaction with waiting time and communication were found to be statistically significant and positively associated with reporting better self-assessed health for respondents in primary care and hospital care settings, respectively in Spain. The marginal effect of a one unit increase in satisfaction with waiting time in primary care and communication in hospital care is associated with a $2 \%$ and $4 \%$ increase in the in the likelihood of reporting very good health status respectively, keeping other variables constant.

Conclusions: Overall, the result suggests that improving patient's satisfaction with health systems responsiveness may have a positive influence on patients' health outcomes.

Keywords: Health system responsiveness; Self-assessed health; Reporting heterogeneity; anchoring vignettes; Spanish Healthcare Barometer

JEL Classification: I10; I12; I18; C30; D13 


\section{Introduction}

Health System Responsiveness has been introduced by the World Health Organization (WHO) as one of the intrinsic goals of the healthcare systems, alongside health outcomes, and fairness of financial contributions [1]. Health system responsiveness as "the way in which individuals are treated and the environment in which they are being treated, encompassing the notion of an individual's experience of contact with the health system" [2]. Responsiveness is a multidimensional concept encompassing eight domains: prompt attention, dignity, communication, autonomy, choice, confidentiality, quality of basic amenities and access to family and community support networks. Prompt attention, communication, and dignity appear to be particularly relevant for the patients' satisfaction with health systems. For instance, they have been rated as the most important among the responsiveness domains by respondents to World Health Survey (a survey launched by the WHO in 2001 and comprising micro-data about 70 countries) $[1,3]$. This study aims to investigate the influence of these three domains of responsiveness on selfassessed health.

Prompt attention, communication and dignity have raised concern in the health policy area in recent years. As an example, waiting time (a facet of Prompt Attention) is a major health policy concern in several OECD countries in general [4-6], and in Spanish National Health System (NHS) in particular. The increase in waiting times for surgery, diagnostic procedures and specialized visits are some of the challenges that the Spanish NHS face currently. For instance, average waiting times for cataract surgery increased - from 89 days in 2010 to 105.1 days in 2015 and for hip replacement increased from 136 to 150.1 days in the same period $[4,7]$. The increase in waiting lists observed in Spanish NHS is likely to be due to the austerity measures adopted by the Spanish government such as budgetary and supply cutbacks $[7,8]$. The Spanish economic recession began in 2008 due to falls in gross domestic products for two consecutive quarters and an increase in the unemployment rate [8]. The austerity measures in 
Spain were implemented in 2010 and this aggravated the situation of the Spanish public healthcare system [8]. Cutbacks in healthcare provision which induce an increase in waiting times might have a potential impact on health outcomes. Reduction of healthcare spending leads to longer average hospital stays, non-attendance at follow up appointments and higher mortality rates. Empirical evidence supporting that longer waiting time for treatments leads to poorer health outcomes [9-11].

Dignity and communication have become a central health policy issue in many parts of the world and its importance to the healthcare system appears to be universal. The WHO survey in 41 countries has found that being treated with dignity appears to be the second most important non-clinical aspects of quality of care next to waiting time [3]. The domain of dignity appears to be particularly relevant in countries where the population is aging at a rapid pace. In the UK, for instance, dignity has become one of the major health issues in relation to older and vulnerable people $[12,13]$. Some study has reported that patients treated with dignity during health care meetings are more likely to report better adherence to treatment, receipt of more optimal preventive care and, finally, to enjoy better health $[14,15]$. However, empirical evidence on this aspect is still needed. In addition to dignity, the importance of effective physician-patient communication for the improvement of patients' health outcomes is well recognized in the literature [16, 17].

Although, the last decade has witnessed a growing body of literature on health systems responsiveness $[2,18,19,19]$, the influence of health system responsiveness on health outcomes has been scarcely investigated and most of the previous studies regarding this relation have focused on a single domain of responsiveness and suggested a mixed result. For example, many studies indicates that a longer waiting time has a negative effect on different health outcomes, such as self-reported health, health gains from surgery measured by EQ-5D index and risk factors for patient mortality see [10, 20, 21]. Other studies such as [5] found no evidence regarding the effect of waiting time on hospital mortality rate and a weak 
effect on emergency readmission rates. Some studies revealed a positive association between communication and health outcome $[16,22,23]$. People who treated with dignity and respect are positively associated with reporting a better health outcome $[14,15]$.

Considering the multidimensionality of health system responsiveness, this paper considers the influence of a set of domains of health system responsiveness on health outcomes - and not just a single domain by exploiting a dataset which is still scarcely investigating, that is the Spanish Healthcare Barometer Survey. Moreover, the study addresses the potential issue of reporting heterogeneity that might affect the self-reported measure of health as a dependent variable. Since self-reported health is measured by an ordered and categorical scale, the interpretation of the response scale may systematically differ across populations or population sub-groups $[18,24,25]$. Such phenomenon has been termed as "reporting heterogeneity" [19, 26, 27] or differential item functioning [28, 29]. This study addresses this issue by estimating a Hierarchical Ordered Probit (HOPIT) model and exploiting vignettes from the World Health Survey (WHS).

The objective of this study is to investigate the linkage between the health system responsiveness and health outcome. Specifically, the study examines if satisfaction with waiting time, dignity and communication affects self-assessed health. 


\section{Methods}

\subsection{The Ordered Probit Model}

Since self-assessed health is measured via self-assessment of individual respondents on an ordinal and categorical scale, the Ordered Probit model can be used to model such a discrete dependent variable which assumes ordered outcomes, e.g., $\mathrm{y}=1,2, . ., \mathrm{m}$.

The ordered Probit model assumes that there is an observed latent variable $Y_{i}^{*}$ distributed with mean $u_{i}$ and variance 1 [30], where $i$ refers to the individual respondent. This can be expressed as:

$$
Y_{i}^{*} \sim N\left(u_{i}, 1\right), \quad i=1, \ldots \ldots, N
$$

The mean level of the latent scale $u_{i}$ is a function for a given covariates.

$$
u_{i}=Z_{i}^{\prime} \beta
$$

Let $y_{i}$ be the observed categorical response of individual $i$ to the main self-report question the ordered probit model can be expressed as [30].

$$
y_{i}=j \text { if } \mu^{j-1} \leq y_{i}^{*}<\mu^{j}, \quad j=1, \ldots
$$

The latent variable $y_{i}^{*}$ is assumed to be a linear function of a vector of variables $Z$ plus a random error term $\varepsilon$ such that

$$
\begin{aligned}
& y_{i}^{*}=Z_{i} \beta+\varepsilon_{i}, \quad \varepsilon_{i} \mid Z_{i} \sim N(0,1), \\
& \text { Where } \mu_{0}=-\infty, \mu^{j}<\mu^{j+1} \text { and } \mu^{k}=+\infty
\end{aligned}
$$

If the assumption of homogenous reporting behavior that is intrinsic in the ordered probit model arises from the constant cut-points does not hold, in particular, if the cut points vary according to some of the covariates, then imposing this restriction will lead to biased estimates of the coefficients $\beta$ in the latent health index since they will reflect both health effect and reporting effects"[31]. 


\subsection{The Hierarchical Ordered Probit model (HOPIT)}

The Hierarchical Ordered Probit model (HOPIT) is applied to identify and correct for reporting heterogeneity. The HOPIT model was developed by [30] and [25] and it is an extension of the Ordered Probit model. The HOPIT model is made of two parts. One part shows the reporting behavior equation (or the vignette component), the other shows the outcome equation (or the main self-assessment component)[18, 19, 32].

The first component or reporting behavior equation of the HOPIT model exploits vignettes to model the cut-points as a function of respondent characteristics. Let $V_{i j}^{r *}$ represent the underlying self-assessed health for vignettes $j$ which is perceived by individual $i$. The vignette component of the likelihood function assumes there is an unobserved latent variable $V_{i j}^{r *}$ distributed with mean $\mu_{i j}^{r}$ and variance 1[30]. Given that each vignette is constant and independent of individual characteristics, it is assumed that the expected value of the underlying latent scale depends solely on the corresponding vignette [18]. The reporting behavior equation can be written as follows:

$$
V_{i j}^{r *}=\mu_{i j}^{v}+\varepsilon_{i k}^{v} \quad \varepsilon_{i k}^{v} \sim N\left(0, \sigma_{\epsilon}^{2}\right)
$$

Where $i$ represent the respondents to the vignette's response, $j$ refers to the vignette number and $v$ represents the vignette component of the model. $\varepsilon_{i k}^{v}$ represent the error term which is normally distributed with mean zero and variance 1 .

If we denote $V_{i j}^{r *}$ the observed self-assessed health by individual $i$ to vignette $j$, the observation mechanism is defined as follows:

$$
V_{i j}^{r *}=k \text { if } \tau_{i}^{k-1} \leq V_{i j}^{r *}<\tau_{i}^{k} ; \text { for } \tau_{i}^{0}=-\infty, \tau_{i}^{5}=\infty \forall i, j \text { and } k=1, \ldots 5
$$

The cut-points can be a function of covariates i.e. $\tau_{i}^{k}=X_{i}^{\prime} \gamma^{k}$.

The second component of the HOPIT model assumes there is an unobserved latent variable $Y_{i}^{s *}$ distributed with mean $\mu_{i}^{S}$ and variance $\sigma^{2}$. The "s" superscript indicates that this component refers to 
self-report questions [30]. In this case, the perceived self-assessed health faced by individual $i$ can be expressed as:

$$
Y_{i}^{s *}=Z_{i} \beta+\varepsilon_{i k}^{S}, \quad \varepsilon_{i k}^{S} \mid Z_{i} \sim N(0,1)
$$

Where $Z_{i}$ represents a set of regressors predicting self-assessed health.

Let $y_{i}^{s}$ be the observed categorical responses on the self-report such that:

$y_{i}^{s}=k$ if $\tau_{i}^{k-1} \leq Y_{i}^{s *}<\tau_{i}^{k} ;$ for $\tau_{i}^{0}=-\infty, \tau_{i}^{5}=\infty \forall i, j$ and $k=1, \ldots 5$

It is assumed that the error terms in the vignette and the latent health equation, $\varepsilon_{i k}^{v}$ and $\varepsilon_{i k}^{s}$ are independent for all $i=1, \ldots 5$ and $k=1, \ldots 5$.

\subsection{Data}

The study sample is selected from the Spanish Healthcare Barometer Survey (SHBS). Every year the SHBS provides information on patient satisfaction with the Spanish National Healthcare System [33]. The SHBS is a population-based cross-sectional survey which collects information on patient satisfaction since 1995. The survey includes rich information on socio-demographic characteristics, occupation, political and health system responsiveness variables. The survey contains information for satisfaction on health system responsiveness in primary care, hospital care and specialized care on three domains of health system responsiveness including Prompt attention (waiting time), communication (clear explanation) and dignity (respectful treatment). For this study, a sample is taken for the year between 2011 and 2013.

\subsubsection{Study variables}

Self-Assessed Health (SAH) is the main outcome variable in this study. SAH is one of the most commonly employed measures of overall individual health [34]. SAH is often considered as a good predictor of objective health and mortality [34-36]. Self-assessed health has been used in the literature to examine the relationship between subjective health and a wide range of socio-economic factors 
including education, income, and employment [37]. In this study, the SHBS respondents were asked to rate their general health condition using the question "How would you describe your state of health in general?". Health is measured on five-point scales since the response categories are "very good", "good", "fair", "bad" and "very bad". For the regression analysis, four categories have been created for this variable by collapsing the "bad" and "very bad" responses categories together as "Bad" response.

The main regressors are the satisfaction with the health system responsive domains variables, which measured on a scale from 1 to 10 , where 1 indicates "completely dissatisfied" and 10 "completely satisfied". For instance, in the domain of waiting time, patients are asked about their "Satisfaction with the amount of time spent by the doctor in your visit". For primary care and specialized care, the SHBS presents four items related to the domains of waiting time (waiting time to make an appointment to visit the doctor, waiting time to carrying out diagnostic tests, the easy to get an appointment and waiting time in the waiting room). For analysis, the average level of satisfaction was considered as a single regressor, which is made by the arithmetic the average of the four items.

Other socio-demographic variables are also used as controls based on previous studies which have addressed the issue of reporting heterogeneity regarding self-assessed health [24, 27, 38-40]. These variables are gender (dummy variable equal to 1 if the respondent is male), age (in years), education (in years), occupation status (dummy variable equal to 1 if the respondent is employed; 0 otherwise) and foreign (dummy equal to 1 if the respondent is foreign; 0 otherwise). Moreover, more objective health conditions of patients which are represented by the variables "previous visits" and "chronic conditions" are also controlled. "Previous visits" indicates if the respondent has visited a general practitioner or a medical specialist in the last 12 months before the interview. Similarly, chronic illness indicates if the survey respondents are affected by chronic conditions. Year dummies and regional dummies have also 
been controlled. The description of all the variables used in this study is reported in Supplementary material S1 Table 1.

On the basis of the study of Harris et al. (2015)[24], vignettes collected through the World Health Survey 2003 [41] and SHARE wave 1 [42] and wave 2 [43] and combine them individually with data about selfreported health in the Spanish Healthcare Barometer Survey to adjust for reporting heterogeneity in selfassessed health. The main self-report assessment from the SHBS and the vignette samples from both the WHS and SHARE were merged by implicitly assuming reporting styles are similar across samples [24]. Vignette questions are asked respondents to evaluate, on the same response scale as the main self-report question. Anchoring vignettes can be used to adjust for reporting heterogeneity and to assess whether differences in rates of self-reports across individuals and socio-economic groups comparable [24, 32, 44, 45]. The full description of the vignettes used in this study can be found in S2 Table 2 .

\subsection{Descriptive statistics}

Table 1 presents the descriptive statistics for respondent characteristics and the health system responsiveness variables based on samples from the Spanish Healthcare Barometer Survey. The sample is restricted to 23,236 respondents of age between 18 and 99 years. $49.17 \%$ of the respondents were male. The average age of the respondents is approximately 47 years old. The average year of education for the respondents in the study is 4.5 years. About $55 \%$ of the respondents reported that their health status is good. Only $29 \%$ of the respondents reported that they have chronic conditions and the majority $71.28 \%$ reported no chronic conditions. The table also shows the descriptive statistics for satisfaction with the health system responsiveness variables using data from the Spanish health care Barometer survey. The result shows that most of the satisfaction variables have a mean of 7 and above on a 10-point scale. This suggests that most of the respondents appear to be satisfied with the respective responsiveness domain (although waiting time reports a lower mean level of satisfaction than the other two domains). 
Table 1. Descriptive Statistics, SHBS (2011-2013)

\begin{tabular}{|l|l|l|l|}
\hline Variable & $\begin{array}{l}\text { Percent/Mean (Std. } \\
\text { Dev.) }\end{array}$ & Min & Max \\
\hline Male & 49.17 & 0 & 1 \\
\hline Age in years (mean) & 47.45 & 18 & 99 \\
\hline Years of education (mean) & 4.54 & 0 & 16 \\
\hline Employed & 40.98 & 0 & 1 \\
\hline Chronic(yes) & 28.72 & 0 & 1 \\
\hline Foreign & 10.25 & 0 & 1 \\
\hline Self-assessed health: Very bad & 0.75 & 0 & 1 \\
\hline Self-assessed health: bad & 3.82 & 0 & 1 \\
\hline Self-assessed health: fair & 22.30 & 0 & 1 \\
\hline Self-assessed health: good & 55.26 & 0 & 1 \\
\hline Self-assessed health: very good & 17.87 & 0 & 1 \\
\hline Independent variables & \multicolumn{3}{|l|}{} \\
\hline Primary care & & \multicolumn{2}{|l|}{} \\
\hline Communication & $7.56(1.89)$ & 1 & 10 \\
\hline Dignity & $7.78(1.77)$ & 1 & 10 \\
\hline Waiting time: doctor & $6.734(2.22)$ & 1 & 10 \\
\hline Waiting time: diagnostic & $5.78(2.34)$ & 1 & 10 \\
\hline Waiting time: appointment & $7.22(2.19)$ & 1 & 10 \\
\hline Waiting time: consultation & $6.03(2.19)$ & 1 & 10 \\
\hline Hospital care & \multicolumn{3}{|l|}{} \\
\hline Communication & $7.28(1.904)$ & 1 & 10 \\
\hline Dignity & $7.33(1.823)$ & 1 & 10 \\
\hline Waiting time & $4.67(2.310)$ & 1 & 10 \\
\hline Specialized care & & \multicolumn{2}{|l|}{} \\
\hline Communication & $7.35(1.97)$ & 1 & 10 \\
\hline Dignity & $7.45(1.80)$ & 1 & 10 \\
\hline Waiting time: specialist & $4.86(2.41)$ & 1 & 10 \\
\hline Waiting time: diagnostic & $5.003(2.379)$ & 1 & 10 \\
\hline Waiting time: appointment & $5.713(2.489)$ & 1 & 10 \\
\hline Waiting time: consultation & $5.669(2.088)$ & 1 & 10 \\
\hline
\end{tabular}

\subsection{Reporting behavior}

This section presents an example of differential reporting behavior of the respondents by their socioeconomic and demographic characteristics. The vignettes selected for illustration here is derived from the WHS mobility and affect domain. The description for this vignette is the following: "[Jan] feels nervous and anxious. He worries and thinks negatively about the future but feels better in the company of people or when doing something that really interests him. When he is alone he tends to feel useless and empty." The corresponding questions for this vignette description are "Overall in the last 30 days, 
how much of a problem did [name of person] have with feeling sad, low, or depressed?". The response categories for such question are "none", "mild", "moderate", "severe" and "extreme". Figure 1 reports bar charts of the rating of this vignette when respondents are stratified by gender, age groups, education, employment status, and citizenship status. Evidence of reporting heterogeneity is shown by observed differences in the reporting of a certain response category by the characteristics of the respondents. The result indicates that there is evidence of differences in reporting behavior particularly across education, employment, and citizenship groups. For example, female respondents are more likely to rate this vignette as very bad than male respondents; better-educated and unemployed respondents are less likely to rate health as bad more likely to rate it as fair compared to the less-educated and the employed respondents. In general, these descriptive results provide prima-facie evidence of the presence of differences in the vignette rating in relation to the socio-demographic characteristics of the respondents.
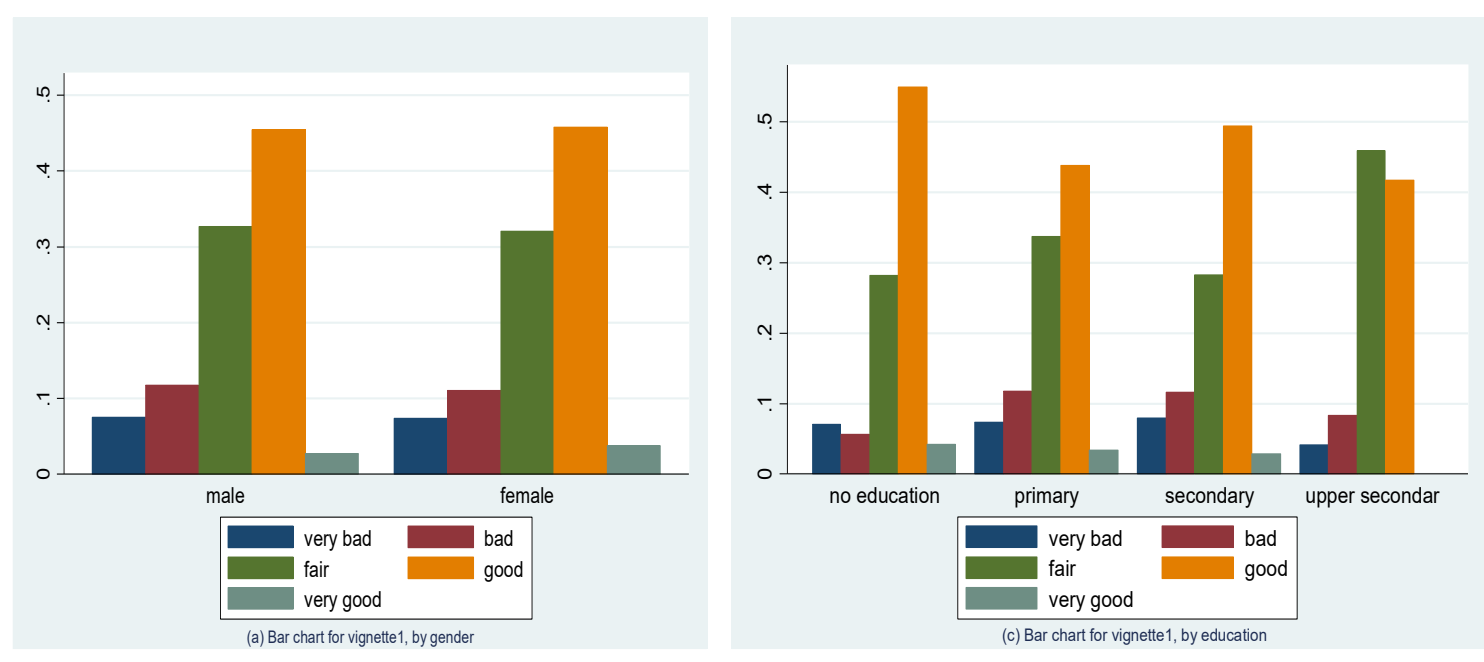

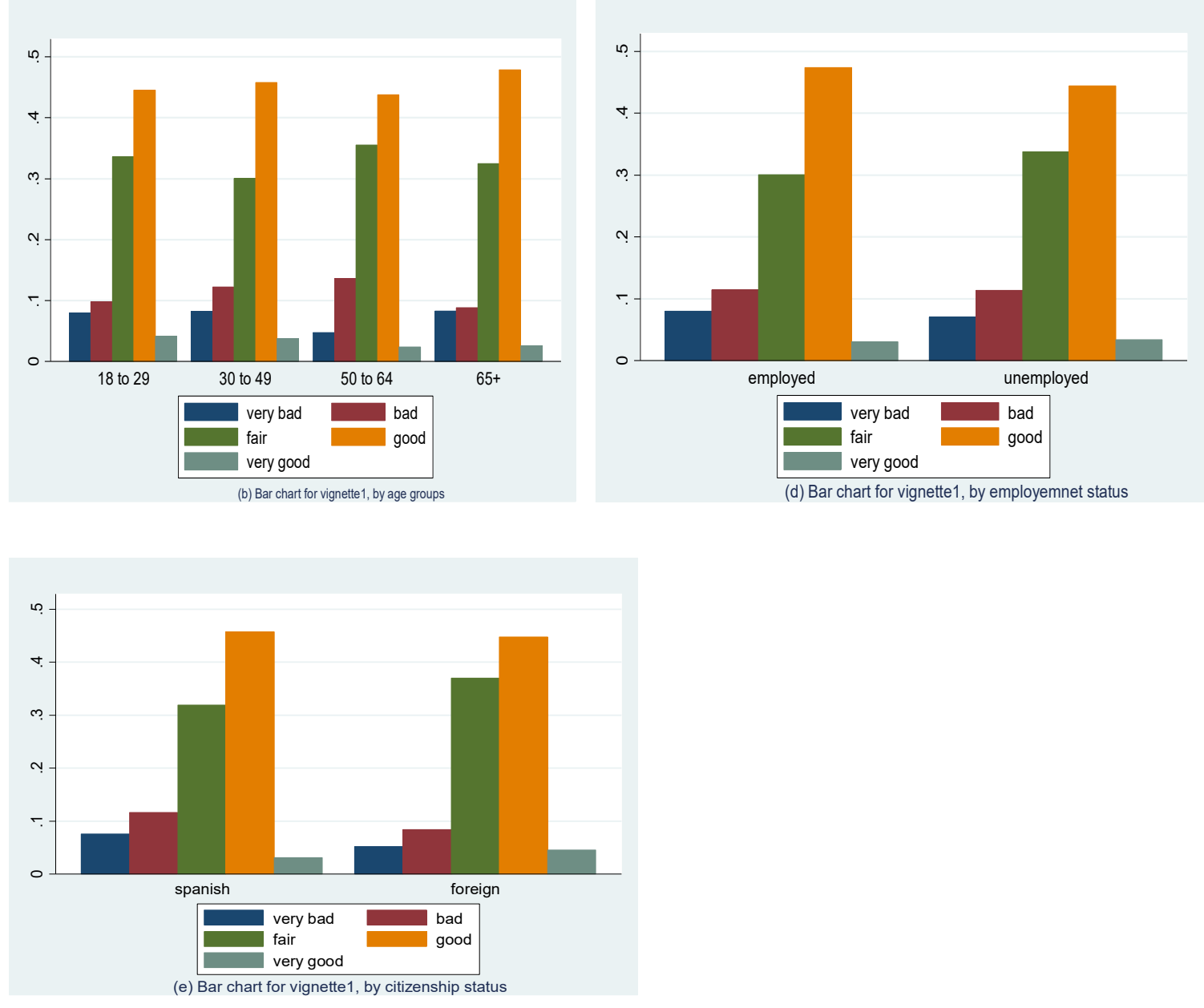

Figure 1. Example of Vignette rating by socio-economic characteristics of the respondents

Source: Author's computation

\section{Results}

Table 2 reports the estimated coefficients and related standard errors for the outcome equation for the Ordered Probit and HOPIT models for the effect of the socio-economic variables (controls) and satisfaction with health system responsiveness domains on health. Three models were compared for primary care, hospital care, and specialized care before adjusting and after adjusting of reporting heterogeneity. The results from the Ordered Probit model - which do not correct for reporting heterogeneity - show that most of the parameter estimates are statistically significant at conventional 
levels $(\leq 5 \%)$. However, for hospital care model satisfaction with waiting time is not statistically significant at all. Results from the Ordered Probit model suggests that men report better health than female, health is decreasing with age and lower education. Previous visits to a doctor and suffering from chronic illnesses are negatively associated with health. The results also show that, when statistically significant, being employed is positively associated with good health status while being foreign with negative health status. Finally, all three domains of responsiveness have a positive and statistically significant influence of good health, apart from waiting time for hospital care.

Since the response categories for self-assessed health and vignette responses range from very bad (worse) to very good (excellent), the lower expectation in the result of the HOPIT model represented by a negative shift in the cut-points. For instance, from the results in Table 2(threshold equation) of the first threshold equation (mu1) the coefficient of being employed is negative and statistically significant for all the models. This indicates that, on average, employed people have a lower threshold between the categories representing very bad and fair self-assessed health. Satisfaction with waiting time is also significant and positive in mul for primary care. Responses to satisfaction with waiting time for primary care and communication for hospital care are likely to affect the reporting behaviour of the respondents. In the second threshold (mu2), the coefficient most covariates are significant for primary care, specialized care, and hospital care models. For instance, for primary care gender, age, education, and employment status are statistically significant and positive, and foreign and waiting time is negative and significant. This means on average positive coefficients represented a higher threshold in the categories between fair and good health status. However, in the last threshold equation (mu3) only education and age are negative and significant for primary care and hospital care respectively. This indicates that educated and older individuals use a lower threshold in the categories between reporting good and very good health status. 
When estimating the HOPIT model, which corrects for reporting heterogeneity, several of the coefficients related to the controls in the outcome equation lose their statistical significance and/or change the magnitude. For instance, being male in an Ordered Probit model is significant at $1 \%$ and $10 \%$ level for hospital care and specialized care, respectively, however it becomes insignificant for HOPIT models. The change in the magnitude and statistical significance of the coefficients in the outcome equation of the HOPIT model reflects the presence of reporting heterogeneity, which is shown in Table 2 (outcome equation). Remember that, since the response categories for self-assessed health and the vignette responses range from "very bad" to "very good", a negative sign for a coefficient related to a given individual character in the threshold equation means that individuals with such characteristic have lower expectation with regard to health and therefore tend to report better health than individuals who don't share such characteristic. When estimating the HOPIT model, most health system responsiveness variables in the outcome equation do not change their sign in comparison to the Ordered Probit model, although there are some changes in the magnitude and statistical significance. The result shows that for primary care and hospital care waiting time affects the reporting style of the individuals. For primary care, the coefficients for this variable are statistically significant and positive and negative in threshold equations $\mathrm{m} 1$ and $\mathrm{m} 2$, respectively. Differently, for hospital care, the coefficient for waiting time is positive and statistically significant in the threshold equation $\mathrm{m} 2$. The overall effect of the correction for this kind of reporting style is that the coefficient for waiting time in the outcome equation in Table 2 (outcome equation) becomes larger. For example, after correcting for the reporting heterogeneity due to satisfaction with waiting times, the effect of waiting time on health appears to be larger for primary care. For hospital care, the reporting style of individuals appears to be affected by satisfaction with communication. Table 2 also shows that for hospital care, the coefficients for communication are statistically significant and positive and negative in threshold equations $\mathrm{m} 1$ and $\mathrm{m} 2$, respectively. The 
overall effect of the correction for this kind of reporting style is that the coefficient for communication in the outcome equation in Table 2 becomes larger.

To check whether correcting for reporting heterogeneity using external vignettes from the 2003 World Health Survey is affected by the specific vignettes a robustness check is run for HOPIT by using externally collected vignettes from the Spanish part of SHARE, wave 1 and 2. The results for the HOPIT model regression for the robustness check are mostly consistent with those obtained when using vignettes from the World Health Survey 2003. The HOPIT regression result using SHARE wave 1 and wave 2 vignettes are presented in S5 Table 5. 
Table 2. Ordered Probit and HOPIT results

\begin{tabular}{|c|c|c|c|c|c|c|}
\hline \multirow{2}{*}{$\begin{array}{l}\text { Outcome } \\
\text { equations }\end{array}$} & \multicolumn{2}{|c|}{ Primary care } & \multicolumn{2}{|c|}{ Hospital care } & \multicolumn{2}{|c|}{ Specialized care } \\
\hline & OPROBIT & HOPIT & OPROBIT & HOPIT & OPROBIT & HOPIT \\
\hline Gender (male) & $\begin{array}{c}0.052^{* *} \\
(0.021)\end{array}$ & $\begin{array}{l}0.240^{*} \\
(0.122)\end{array}$ & $\begin{array}{c}0.071^{* * *} \\
(0.019)\end{array}$ & $\begin{array}{c}0.222 \\
(0.147)\end{array}$ & $\begin{array}{l}0.038^{*} \\
(0.017)\end{array}$ & $\begin{array}{c}0.196 \\
(0.128)\end{array}$ \\
\hline Age (years) & $\begin{array}{c}-0.016^{* * *} \\
(0.001) \\
\end{array}$ & $\begin{array}{c}-0.0139 * * * \\
(0.004)\end{array}$ & $\begin{array}{c}-0.0153 * * * \\
(0.001)\end{array}$ & $\begin{array}{l}-0.007 \\
(0.005) \\
\end{array}$ & $\begin{array}{c}-0.016^{* * *} \\
(0.001)\end{array}$ & $\begin{array}{l}-0.011^{*} \\
(0.004)\end{array}$ \\
\hline $\begin{array}{c}\text { Education } \\
\text { (years) }\end{array}$ & $\begin{array}{c}0.059 * * * \\
(0.003)\end{array}$ & $\begin{array}{c}0.099 * * * \\
(0.023)\end{array}$ & $\begin{array}{c}0.060 * * * \\
(0.004)\end{array}$ & $\begin{array}{c}0.098 * * * \\
(0.027)\end{array}$ & $\begin{array}{c}0.066^{* * *} \\
(0.004)\end{array}$ & $\begin{array}{c}0.092 * * * \\
(0.024)\end{array}$ \\
\hline Employed (yes) & $\begin{array}{c}0.097 * * * \\
(0.018)\end{array}$ & $\begin{array}{l}-0.231 \\
(0.135) \\
\end{array}$ & $\begin{array}{c}0.132 * * * \\
(0.021)\end{array}$ & $\begin{array}{l}-0.347 \\
(0.163) \\
\end{array}$ & $\begin{array}{c}0.121 * * * \\
(0.019)\end{array}$ & $\begin{array}{l}-0.186 \\
(0.142)\end{array}$ \\
\hline Foreign (yes) & $\begin{array}{c}-0.125^{* * *} \\
(0.028)\end{array}$ & $\begin{array}{c}-0.0824 \\
(0.209) \\
\end{array}$ & $\begin{array}{c}-0.0839^{*} \\
(0.035)\end{array}$ & $\begin{array}{c}0.362 \\
(0.265) \\
\end{array}$ & $\begin{array}{c}-0.139^{* * * *} \\
(0.029)\end{array}$ & $\begin{array}{c}-0.001 \\
(0.224) \\
\end{array}$ \\
\hline Previous visits & $\begin{array}{c}-0.339 * * * \\
(0.019)\end{array}$ & $\begin{array}{c}-0.340^{* * *} \\
(0.019) \\
\end{array}$ & $\begin{array}{c}-0.405^{* * *} \\
(0.030) \\
\end{array}$ & $\begin{array}{c}-0.318^{* * * *} \\
(0.034)\end{array}$ & $\begin{array}{c}-0.312 * * * \\
(0.017)\end{array}$ & $\begin{array}{c}-0.291 * * * \\
(0.018) \\
\end{array}$ \\
\hline Chronic ill-ness & $\begin{array}{c}-1.023 * * * \\
(0.019)\end{array}$ & $\begin{array}{c}-0.919 * * * \\
(0.022) \\
\end{array}$ & $\begin{array}{c}-1.039^{* * *} \\
(0.023)\end{array}$ & $\begin{array}{c}-0.932 * * * \\
(0.0245)\end{array}$ & $\begin{array}{c}-1.005^{* * *} \\
(0.021)\end{array}$ & $\begin{array}{c}-0.903 * * * \\
(0.022) \\
\end{array}$ \\
\hline Communication & $\begin{array}{c}0.038 * * * \\
(0.006)\end{array}$ & $\begin{array}{c}0.037 * * * \\
(0.006) \\
\end{array}$ & $\begin{array}{c}0.048 * * * \\
(0.006)\end{array}$ & $\begin{array}{c}0.129 * * \\
(0.042)\end{array}$ & $\begin{array}{c}0.023 * * * \\
(0.007)\end{array}$ & $\begin{array}{c}0.025 * * * \\
(0.007)\end{array}$ \\
\hline Dignity & $\begin{array}{c}0.022 * * * \\
(0.006)\end{array}$ & $\begin{array}{c}0.022 * * * \\
(0.007)\end{array}$ & $\begin{array}{c}0.025 * * * \\
(0.007)\end{array}$ & $\begin{array}{c}0.027 * * * \\
(0.007)\end{array}$ & $\begin{array}{c}0.028 * * * \\
(0.007)\end{array}$ & $\begin{array}{c}0.029 * * * \\
(0.008)\end{array}$ \\
\hline Waiting time & $\begin{array}{c}0.028^{* * *} \\
(0.006)\end{array}$ & $\begin{array}{c}0.105^{* *} \\
(0.036)\end{array}$ & $\begin{array}{c}0.007 \\
(0.004)\end{array}$ & $\begin{array}{l}-0.019 \\
(0.034)\end{array}$ & $\begin{array}{c}0.024 * * * \\
(0.006)\end{array}$ & $\begin{array}{c}0.022 * * * \\
(0.006)\end{array}$ \\
\hline Year dummy & yes & yes & yes & yes & yes & yes \\
\hline Region dummy & yes & yes & yes & yes & yes & yes \\
\hline Constant & & $\begin{array}{c}1.034 * * * \\
(0.069)\end{array}$ & & $\begin{array}{c}0.821 * * * \\
(0.079)\end{array}$ & & $\begin{array}{c}0.884 * * * \\
(0.067)\end{array}$ \\
\hline \multicolumn{7}{|c|}{ Cut-point constants } \\
\hline cut1_cons & $\begin{array}{c}-2.560 * * * \\
(0.059)\end{array}$ & & $\begin{array}{c}-2.327 * * * \\
(0.065)\end{array}$ & & $\begin{array}{c}-2.49 * * * \\
(0.058)\end{array}$ & \\
\hline cut2_cons & $\begin{array}{c}-1.131^{* * *} \\
(0.056)\end{array}$ & & $\begin{array}{c}-0.907 * * * \\
(0.062)\end{array}$ & & $\begin{array}{c}-1.052^{* * * *} \\
(0.056)\end{array}$ & \\
\hline cut3_cons & $\begin{array}{c}0.812 * * * \\
(0.056)\end{array}$ & & $\begin{array}{c}1.038^{* * *} * \\
(0.062)\end{array}$ & & $\begin{array}{c}0.908 * * * \\
(0.056)\end{array}$ & \\
\hline \multicolumn{7}{|c|}{ Vignettes constants } \\
\hline Vignette 1 & & $\begin{array}{c}2.528 * * * \\
(0.356)\end{array}$ & & $\begin{array}{c}2.675 * * * \\
(0.441)\end{array}$ & & $\begin{array}{c}1.997 * * * \\
(0.301)\end{array}$ \\
\hline Vignette 2 & & $\begin{array}{c}-3.579 * * * \\
(0.389)\end{array}$ & & $\begin{array}{c}-3.493 * * * \\
(0.479)\end{array}$ & & $\begin{array}{c}-4.180 * * * \\
(0.354)\end{array}$ \\
\hline Vignette 3 & & $\begin{array}{c}5.633 * * * \\
(0.385)\end{array}$ & & $\begin{array}{c}5.822 * * * \\
(0.476)\end{array}$ & & $\begin{array}{c}5.177 * * * \\
(0.332)\end{array}$ \\
\hline Vignette 4 & & $\begin{array}{c}8.670^{* * *} \\
(0.442)\end{array}$ & & $\begin{array}{c}8.975 * * * \\
(0.546)\end{array}$ & & $\begin{array}{c}8.202 * * * \\
(0.397) \\
\end{array}$ \\
\hline Vignette 5 & & $\begin{array}{c}8.970 * * * \\
(0.449)\end{array}$ & & $\begin{array}{c}9.302 * * * \\
(0.555) \\
\end{array}$ & & $\begin{array}{c}8.530 * * * \\
(0.406) \\
\end{array}$ \\
\hline Constant & & $3.207 * * *$ & & $3.300 * * *$ & & $3.267 * * *$ \\
\hline
\end{tabular}


\begin{tabular}{|l|l|l|l|l|l|l|}
\hline & & $(0.109)$ & & $(0.133)$ & & $(0.115)$ \\
\hline
\end{tabular} 
Table 2 continued... HOPIT Estimated coefficients of covariates in the cut-points (Threshold equations)

\begin{tabular}{|c|c|c|c|c|c|c|c|c|c|}
\hline \multirow{2}{*}{$\begin{array}{l}\text { Threshold } \\
\text { equations }\end{array}$} & \multicolumn{3}{|c|}{ Primary care } & \multicolumn{3}{|c|}{ Hospital care } & \multicolumn{3}{|c|}{ Specialized care } \\
\hline & mu1 & $\mathrm{mu} 2$ & mu3 & mul & mu2 & mu3 & mu1 & $\mathrm{mu} 2$ & mu3 \\
\hline Gender (male) & $\begin{array}{c}0.147 \\
(0.122)\end{array}$ & $\begin{array}{c}0.041 * * \\
(0.014)\end{array}$ & $\begin{array}{c}-0.031 \\
(0.038)\end{array}$ & $\begin{array}{c}0.115 \\
(0.147)\end{array}$ & $\begin{array}{l}0.033^{*} \\
(0.017)\end{array}$ & $\begin{array}{l}0.004 \\
(0.05)\end{array}$ & $\begin{array}{c}0.109 \\
(0.128)\end{array}$ & $\begin{array}{c}0.043 * * \\
(0.015)\end{array}$ & $\begin{array}{l}-0.038 \\
(0.039)\end{array}$ \\
\hline Age (years) & $\begin{array}{c}0.002 \\
(0.004)\end{array}$ & $\begin{array}{c}0.001 * * \\
(0.001)\end{array}$ & $\begin{array}{c}-0.001 \\
(0.001) \\
\end{array}$ & $\begin{array}{c}0.009 \\
(0.005) \\
\end{array}$ & $\begin{array}{c}0.001 \\
(0.001) \\
\end{array}$ & $\begin{array}{c}-0.003 * \\
(0.001) \\
\end{array}$ & $\begin{array}{c}0.005 \\
(0.004) \\
\end{array}$ & $\begin{array}{c}0.001 * \\
(0.001)\end{array}$ & $\begin{array}{c}-0.001 \\
(0.001) \\
\end{array}$ \\
\hline Education & $\begin{array}{c}0.013 \\
(0.022)\end{array}$ & $\begin{array}{c}0.023 * * * \\
(0.003)\end{array}$ & $\begin{array}{c}-0.014^{*} \\
(0.007) \\
\end{array}$ & $\begin{array}{c}0.012 \\
(0.027) \\
\end{array}$ & $\begin{array}{c}0.022 * * * \\
(0.003)\end{array}$ & $\begin{array}{l}-0.009 \\
(0.008)\end{array}$ & $\begin{array}{c}-0.001 \\
(0.024) \\
\end{array}$ & $\begin{array}{c}0.022 * * * \\
(0.003)\end{array}$ & $\begin{array}{l}-0.009 \\
(0.007)\end{array}$ \\
\hline Employed & $\begin{array}{c}-0.380 * * \\
(0.136)\end{array}$ & $\begin{array}{c}0.080 * * * \\
(0.015)\end{array}$ & $\begin{array}{c}0.048 \\
(0.042)\end{array}$ & $\begin{array}{c}-0.525 * * \\
(0.163)\end{array}$ & $\begin{array}{c}0.081^{* * *} * \\
(0.018)\end{array}$ & $\begin{array}{c}0.071 \\
(0.049)\end{array}$ & $\begin{array}{c}-0.356^{*} \\
(0.142)\end{array}$ & $\begin{array}{c}0.082 * * * \\
(0.016)\end{array}$ & $\begin{array}{c}0.037 \\
(0.044)\end{array}$ \\
\hline Foreign & $\begin{array}{c}0.169 \\
(0.209) \\
\end{array}$ & $\begin{array}{c}-0.098 * * * \\
(0.024)\end{array}$ & $\begin{array}{c}0.023 \\
(0.064)\end{array}$ & $\begin{array}{c}0.573 * \\
(0.265) \\
\end{array}$ & $\begin{array}{c}-0.110 * * * \\
(0.031)\end{array}$ & $\begin{array}{l}-0.026 \\
(0.082)\end{array}$ & $\begin{array}{c}0.264 \\
(0.224) \\
\end{array}$ & $\begin{array}{c}-0.103 * * * \\
(0.025)\end{array}$ & $\begin{array}{c}0.025 \\
(0.069)\end{array}$ \\
\hline Commu & & & & $\begin{array}{c}0.095 * \\
(0.042) \\
\end{array}$ & $\begin{array}{c}-0.021 * * * \\
(0.005)\end{array}$ & $\begin{array}{c}0.009 \\
(0.013) \\
\end{array}$ & & & \\
\hline Waiting time & $\begin{array}{c}0.083 * \\
(0.035)\end{array}$ & $\begin{array}{c}-0.009 * \\
(0.004)\end{array}$ & $\begin{array}{c}-0.008 \\
(0.011) \\
\end{array}$ & $\begin{array}{c}-0.033 \\
(0.034) \\
\end{array}$ & $\begin{array}{c}0.011 * * \\
(0.004) \\
\end{array}$ & $\begin{array}{c}0.005 \\
(0.010) \\
\end{array}$ & & & \\
\hline Constant & $\begin{array}{c}0.710 * * * \\
(0.096)\end{array}$ & $\begin{array}{c}0.540 * * * \\
(0.037)\end{array}$ & $\begin{array}{c}1.498 * * * \\
(0.113)\end{array}$ & $\begin{array}{c}0.795 * * * \\
(0.115)\end{array}$ & $\begin{array}{c}0.594 * * * \\
(0.0450)\end{array}$ & $\begin{array}{c}1.397 * * * \\
(0.136)\end{array}$ & $\begin{array}{c}0.554 * * * \\
(0.080)\end{array}$ & $\begin{array}{c}0.488 * * * \\
(0.031)\end{array}$ & $\begin{array}{c}1.435^{* * *} * \\
(0.097)\end{array}$ \\
\hline Observations & 20463 & 20463 & 20463 & 14937 & 14937 & 14937 & 19129 & 19129 & 19129 \\
\hline
\end{tabular}

Standard errors in parentheses; ${ }^{* * *} \mathrm{p}<0.01,{ }^{* *} \mathrm{p}<0.05,{ }^{*} \mathrm{p}<0$.

Since the coefficients in the Probit and HOPIT model regressions have only a qualitative interpretation, information about the quantitative effect of the variables used as regressors are provided by computing marginal effects for continuous variables and average partial effects for binary variables. Table 3 presents the marginal effect of satisfaction with health system responsiveness domains on the probability of reporting very good self-assessed health status for patients treated with primary care, hospital care, and specialized care models. The average individual who is taken as a reference to calculate these effects is male, aged 64, educated, employed and foreigner. 
Table 3. Marginal effects

\begin{tabular}{|c|c|c|c|c|c|c|}
\hline \multirow{2}{*}{ Variables } & \multicolumn{2}{|c|}{ Primary care } & \multicolumn{2}{c|}{ Hospital care } & \multicolumn{2}{c|}{ Specialized care } \\
\cline { 2 - 7 } & Probit & HOPIT & Probit & HOPIT & Probit & HOPIT \\
\hline Communication & $0.009 * * *$ & $0.007 *$ & $0.011^{* * *}$ & $0.039 * *$ & $0.005^{* * *}$ & $0.005^{*}$ \\
& $(0.001)$ & $(0.003)$ & $(0.001)$ & $(0.015)$ & $(0.001)$ & $(0.002)$ \\
\hline Dignity & $0.004^{* * *}$ & $0.004^{*}$ & $0.005^{* * *}$ & $0.008^{* *}$ & $0.006^{* * *}$ & $0.006^{*}$ \\
& $(0.001)$ & $(0.002)$ & $(0.001)$ & $(0.003)$ & $(0.001)$ & $(0.002)$ \\
\hline Waiting time & $0.005^{* * *}$ & $0.020^{*}$ & 0.001 & -0.006 & $0.004 * * *$ & $0.005^{*}$ \\
& $(0.001)$ & $(0.008)$ & $(0.001)$ & $(0.009)$ & $(0.001)$ & $(0.002)$ \\
\hline
\end{tabular}

Standard errors in parentheses; $* * * \mathrm{p}<0.01, * * \mathrm{p}<0.05, * \mathrm{p}<0.1$

All the marginal effects in Table 3 are positive and statistically significant, apart from satisfaction with waiting time in hospital care. After adjusting for reporting heterogeneity, there are some changes in the magnitude and significance of the coefficients. For instance, when looking at the Ordered Probit model, for the domains of satisfaction with communication, dignity and waiting time a one unit increase in satisfaction with these domains (which range from 1 to 10 ) is associated with a $0.9 \%, 0.44 \%$ and $0.5 \%$ increase in the likelihood of reporting very good health in primary care, and $0.5 \%, 0.6 \%$ and $0.4 \%$ in specialized care respectively, keeping other variables constant. After adjusting for reporting heterogeneity, this percentage goes up to $2 \%$ for waiting time in primary care and to about $4 \%$ for communication in hospital care. Therefore, the positive effect of the satisfaction with these domains of responsiveness on health appears to be larger after correcting for reporting heterogeneity. The full description of the marginal and average partial effects for all the variables included in the regression model is available in S4 Table 4.

\section{Discussion}

Using data from the Spanish Healthcare Barometer Survey (SHBS), this paper investigates the effect of three domains of health system responsiveness (communication, dignity and waiting times) on selfassessed health. The self-reports of the respondents appear to be affected by their reporting style, which varies because of their individual and socioeconomic variables such as education, age, and gender. After 
adjusting for this phenomenon of reporting heterogeneity, significant and positive association between the domains of health system responsiveness and self-assessed health is observed for in primary, hospital and specialized care. The study results are consistent with some of the previous studies on a single domain of responsiveness. For example, satisfied patients regarding the information given by their doctors and those who have good communication with them are more likely to complete treatment regimens and to be compliant and cooperative $[16,22,46]$. Being treated with dignity and being involved in decisions are independently associated with positive health outcomes [14].

This study contributes to the literature in several ways. Most of the previous studies which have investigated the determinants of self-assessed health have mainly focused on its socioeconomic determinants. However, since the WHO introduced the concept of health system responsiveness in 2000, if responsiveness has an impact on health has not been very well investigated empirically. The study investigates this research question by exploiting a novel dataset, the Spanish Healthcare Barometer Survey (SHBS). Moreover, it addresses the issue of reporting heterogeneity that arises from using a selfreported measure of health as a dependent variable by exploiting anchoring vignettes and estimating a HOPIT model.

This study is not without limitations. First, the transmission mechanisms through which the domains of responsiveness may influence health still need further investigation. Especially, the relationship between dignity and health outcome has received little attention from previous literature and the pathway linking dignity to health needs to study more thoroughly. Second, ideally, when using externally collected vignettes and merging them to a dataset to adjust for reporting heterogeneity, the vignettes should be collected in the same year and country as the main dataset [24]. This study used vignettes that, although collected in the same country as the main dataset, were collected in a different year. However, this study addressed this issue by performing, on the top of the main analysis conducted using vignettes from the 
WHS, robustness checks run by using two set of vignettes from SHARE, collected in wave 1 and wave

2.

\section{Conclusions}

Overall, this study suggests that improving the way in which patients are treated in the health care system have a positive health outcome. This can be an important implication for health policy. For instance, patients who satisfied with waiting time or older individuals who treated respectfully during medical treatment are more likely to have a better health outcome. This work contributes to a growing body of research examining the influence of health system responsiveness on health and provides a rich foundation for future research and health interventions.

\section{List of abbreviations}

DIF: Differential Item Functioning; EQ-5D: EuroQol-Five Dimensions; HOPIT: Hierarchical Ordered Probit Model; HSR: Health System Responsiveness; MESS: Multi Country Survey Study; NHS: National Health System; Oprobit: Ordered Probit; SAH: Self-assessed Health; SHARE: Survey of Health, Aging and Retirement in Europe; WHO: World Health Organization; WHR: World Health Report; WHS: World Health Survey

\section{Ethics approval and consent to participate}

Not applicable

\section{Consent for publication}

Not applicable

\section{Availability of data and materials}

The datasets used and/or analyzed during the current study are available from the corresponding author on reasonable request. 


\section{Competing interests}

The authors declare that they have no competing interests.

\section{Funding}

No funding was received towards this work.

\section{Authors' contributions}

SK contributed towards the study's design, methodology and execution of the research, analysis and interpretation of the data and writing the manuscript. The author read and approved the final manuscript.

\section{Acknowledgements}

Not applicable 


\section{References}

1. WHO, editor. The World Health Report 2000: health systems: improving performance. Geneva: WHO; 2000.

2. Valentine NB, de Silva A, Kawabata K, Darby C, Murray CJL, Evans DB. Health System Responsiveness: Concepts, Domains and Operationalization. 2003;:110.

3. Valentine N, Darby C, Bonsel GJ. Which aspects of non-clinical quality of care are most important? Results from WHO's general population surveys of "health systems responsiveness" in 41 countries. Soc Sci Med. 2008;66:1939-50.

4. Gutacker N, Siciliani L, Cookson R. Waiting time prioritisation: Evidence from England. Soc Sci Med. 2016;159:140-51.

5. Moscelli G, Siciliani L, Tonei V. Do waiting times affect health outcomes? Evidence from coronary bypass. Soc Sci Med. 2016;161:151-9.

6. Siciliani L, Moran V, Borowitz M. Measuring and comparing health care waiting times in OECD countries. Health Policy. 2014;118:292-303.

7. Bernal E, Sandra D, Juan G-A, Fernando O, Sánchez Martínez I, Ramón J, et al. Spain Health system review. Health Syst Transit. 2018;20. www.healthobservatory.eu.

8. Borra C, Pons-Pons J, Vilar-Rodriguez M. Austerity, health care provision, and health outcomes in Spain. 2017.

9. Moscelli G, Siciliani L, Tonei V. Do waiting times affect health outcomes? Evidence from coronary bypass. Soc Sci Med. 2016;161:151-9.

10. Nikolova S, Harrison M, Sutton M. The Impact of Waiting Time on Health Gains from Surgery: Evidence from a National Patient-reported Outcome Dataset. Health Econ. 2016;25:955-68.

11. Reichert A, Jacobs R. The impact of waiting time on patient outcomes: Evidence from early intervention in psychosis services in England. Health Econ U K. 2018;27:1772-87.

12. Gallagher A, Li S, Wainwright P, Jones IR, Lee D. Dignity in the care of older people - A review of the theoretical and empirical literature. BMC Nurs. 2008;7:1-12.

13. Tauber-Gilmore M, Addis G, Zahran Z, Black S, Baillie L, Procter S, et al. The views of older people and health professionals about dignity in acute hospital care. J Clin Nurs. 2018;27:223-34.

14. Beach MC, Sugarman J, Johnson RL, Arbelaez JJ, Duggan PS, Cooper LA. Do patients treated with dignity report higher satisfaction, adherence, and receipt of preventive care? Ann Fam Med. 2005;3:331-8.

15. Beach MC, Duggan PS. Receipt of Preventive Care ? 2005;:331-8. 
16. Stewart M, Brown JB, Donner A, McWhinney IR, Oates J, Weston WW, et al. The impact of patient-centered care on outcomes. J Fam Pract. 2000;49 November 1996:796-804.

17. Stewart MA. EFFECTIVE PHYSICIAN-PATIENT COMMUNICATION AND HEALTH OUTCOMES: A REVIEW Objectif: Determiner si la qualite de la communication medecin-patient a un effet important sur la. Can Med Assoc J. 1995;152:1423-33.

18. Rice N, Robone S, Smith PC. Vignettes and health systems responsiveness in cross-country comparative analyses. J R Stat Soc Ser A Stat Soc. 2012;175:337-69.

19. Rice N, Robone S, Smith P. Analysis of the validity of the vignette approach to correct for heterogeneity in reporting health system responsiveness. Eur J Health Econ. 2011;12:141-62.

20. Howell JL, Sweeny K. Is waiting bad for subjective health? J Behav Med. 2016;39:652-64.

21. Meier-Kriesche HU, Port FK, Ojo AO, Rudich SM, Hanson JA, Cibrik DM, et al. Effect of waiting time on renal transplant outcome. Kidney Int. 2000;58:1311-7.

22. Kaplan SH, Greenfield S, Ware J. Assessing the Effects of Physician-Patient Interactions on the Outcomes of Chronic Disease Author ( s ): Sherrie H . Kaplan, Sheldon Greenfield, John E. Ware and Jr . Published by : Lippincott Williams \& Wilkins Stable URL : http://www.jstor.org/stable. Med Care. 1989;27:S110-27.

23. Lee Y-Y, Lin JL. How much does trust really matter? A study of the longitudinal effects of trust and decision-making preferences on diabetic patient outcomes. Patient Educ Couns. 2011;85:406-12.

24. Harris MN, Knott R, Lorgelly P, Rice N. Survey self-assessments, reporting behaviour and the use of externally collected vignettes. Bank Curtin Econ Cent. 2015;:1-26.

25. King G, Murray CJL, Salomon JA, Tandon A. Enhancing the Validity and Cross-Cultural Comparability of Measurement in Survey Research. Am Polit Sci Rev. 2004;98:191-207.

26. d'Uva TB, Lindeboom M, O'Donnell O, Van Doorslaer E. Slipping anchor? Testing the vignettes approach to identification and correction of reporting heterogeneity. J Hum Resour. 2011;46:875-906.

27. Rossouw L, Bago d'Uva T, van Doorslaer E. Poor Health Reporting? Using Vignettes to Recover the Health Gradient by Wealth. Ssrn. 2017;:1935-56.

28. Kapteyn A, Smith JP. Anchoring Vignettes and Response Consistency. 2011; February.

29. Luo N, Johnson JA, Shaw JW, Feeny D, Coons SJ. Self-reported health status of the general adult US population as assessed by the EQ-5D and Health Utilities Index. Med Care. 2005;:1078-86.

30. Tandon A, Murray C, Salomon J, King G. Statistical models for enhancing cross-population comparability. Health Syst Perform Assess Debates Methods Empiricism. 2003;:1-37.

31. Jones AM, Rice N, d'Uva TB, Balia S. Applied health economics. Routledge; 2013. 
32. King G, Murray CJL, Salomon JA, Tandon A. Enhancing the Validity and Cross-Cultural Comparability of Measurement in Survey Research. Am Polit Sci Rev. 2004;98:191-207.

33. Ministry of Health. Ministry of Health, Social Services and Equality (Spain), Sociological Research Center (Spain). 2016.

34. Au N, Johnston DW. Self-assessed health: what does it mean and what does it hide? Soc Sci Med 1982. 2014;121:21-8.

35. Paul P, Hakobyan M, Valtonen H. The association between self-perceived health status and satisfaction with healthcare services: Evidence from Armenia. BMC Health Serv Res. 2016;16:67.

36. Pfarr C, Schmid A, Schneider U. Reporting heterogeneity in self-assessed health among elderly Europeans. Health Econ Rev. 2012;2:21.

37. Contoyannis P, Jones AM, Rice N. The dynamics of health in the British Household Panel Survey. J Appl Econom. 2004;19:473-503.

38. Bago d'Uva T, O’Donnell O, Van doorslaer E. Differential health reporting by education level and its impact on the measurement of health inequalities among older Europeans. Int J Epidemiol. 2008;37:1375-83.

39. Lorgelly P, Knott R. Adjusting for Differential Item Functioning in the EQ-5Q-5L using Externally-Collected Vignettes. 2017; July.

40. Xu H, Xie Y. Assessing the Effectiveness of Anchoring Vignettes in Bias Reduction for Socioeconomic Disparities in Self-Rated Health among Chinese Adults. Sociol Methodol. 2016;46:84120.

41. The World Health Survey 2003.World Health Organization. 2012. http://apps.who.int/healthinfo/systems/surveydata/index.php/catalog/130/study-description.

42. Börsch-Supan A. Survey of Health, Ageing and Retirement in Europe (SHARE) wave 1. Release Version. 2018;6.1.1.SHARE-ERIC. Data set.

43. Börsch-Supan A. Survey of Health, Ageing and Retirement in Europe (SHARE) Wave 2. Release version: 6.1. 1. SHARE-ERIC. Data Set. 2018.

44. Salomon JA. Comparability of self rated health: cross sectional multi-country survey using anchoring vignettes. Bmj. 2004;328:258-0.

45. Tandon A, Murray C, Salomon J, King G. Statistical models for enhancing cross-population comparability. Health Syst Perform Assess Debates Methods Empiricism. 2003;:1-37.

46. Bleich SN, Ozaltin E, Murray CJL. How does satisfaction with the health-care system relate to patient experience? Bull World Health Organ. 2009;87:271-8. 
Figures
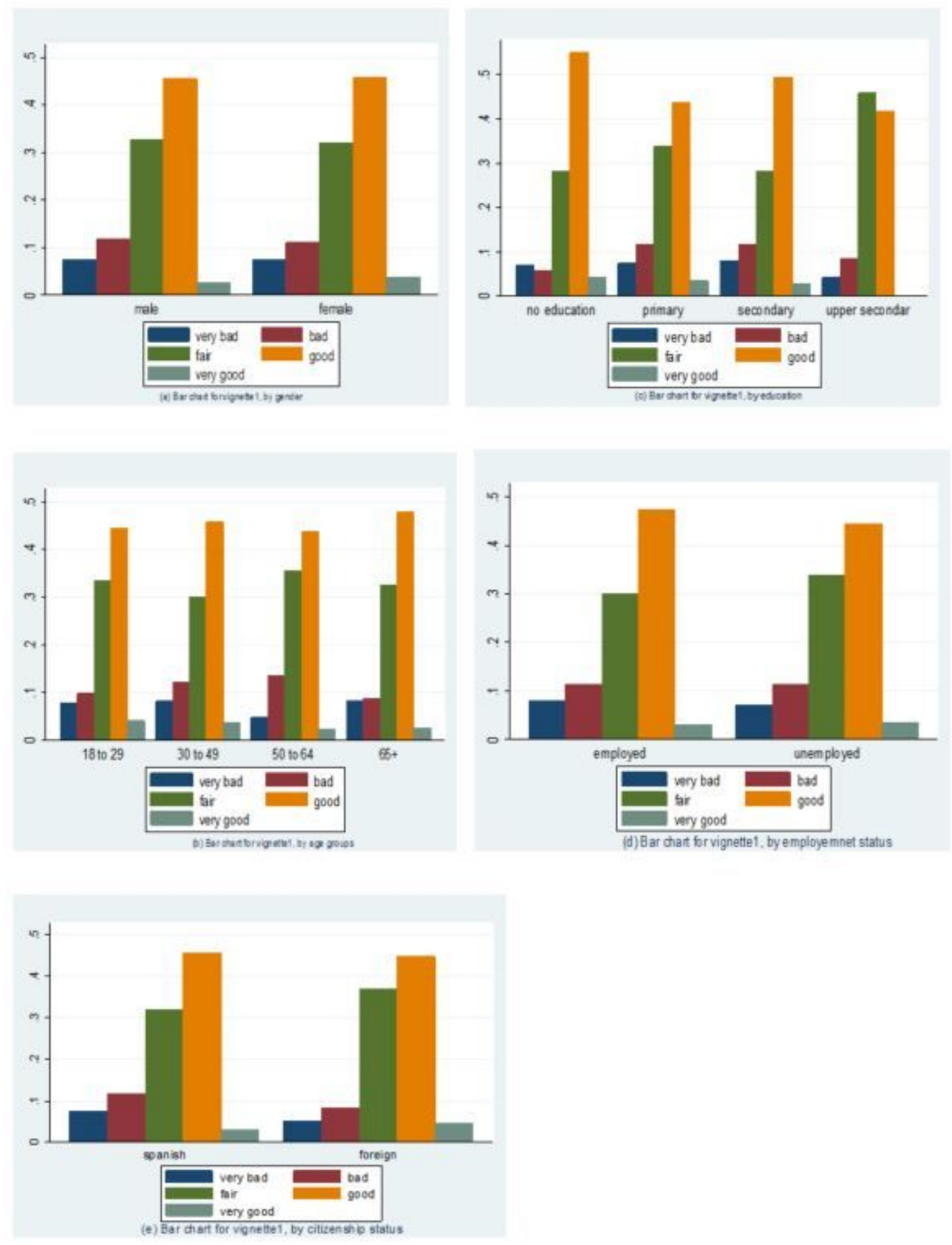

Figure 1

Example of Vignette rating by socio-economic characteristics of the respondents Source: Author's computation 


\section{Supplementary Files}

This is a list of supplementary files associated with this preprint. Click to download.

- Supplementarymaterial.docx 